IV Congreso Internacional Estética y Política Poéticas del desacuerdo para una democracia plural 16 y 17 de octubre. Valencia

Doi: http://dx.doi.org/10.4995/CEP4.2019.10514

\title{
Imágenes en conflicto: el fenómeno iconoclasta como teoría del disenso
}

\section{Sergio Martín}

Alumno Máster en Producción Artística, Universitat Politècnica de València. sergemartinezmartin@gmail.com

\begin{abstract}
Recent studies have tried to deepen two fundamental concepts in the historical study of human culture: image and iconoclasm. Initially sections of the academic canons taught since the History of Art, have been deconstructed by new theoretical currents such as visual studies or the science of image. Due to this openness towards new perspectives on artistic objects and practices, the phenomenon baptized as the destruction of art or, commonly known as iconoclastic phenomena, has begun to be examined more closely. Understood as related acts on the basis of the religious foundation, they became laboratories of some of the crises on representation through artistic practice and the reaction to it. So, currently, these kinds of events are being reviewed to extend the limits in which they used to be classified: ranging from religious disputes to mere emotional and vandalism attacks. Therefore, this paper seeks to approach another view on the iconoclasm that has in mind the theories about the surplus value of images shared by authors such as W.J.T Mitchell or David Freedberg. For this purpose, it is about finding other definitions of the violent act against images, making this phenomenon a possible theory of dissent. In this way, a field of study that analyzes destructive events as a scenario of agonism that articulates changes in social communities from their own representations and the thinking behind them is defended.
\end{abstract}

Keywords: Iconoclasm, Dissent, Imagen, Culture History

\begin{abstract}
Resumen
Recientes estudios han tratado de profundizar en dos conceptos fundamentales en el estudio histórico de la cultura humana: la imagen y la iconoclasia. Apartados en un principio de los cánones académicos impartidos desde la Historia del Arte, han sido deconstruidos por nuevas corrientes teóricas como los estudios visuales o la ciencia de la imagen. Debido a esta apertura hacia nuevas perspectivas sobre los objetos y prácticas artísticas, se ha comenzado a revisar más de cerca el fenómeno bautizado como la destrucción del arte o, comúnmente conocido, como los fenómenos iconoclastas. Entendidos como actos relacionados sobre bases del fundamento religioso, se convirtieron en laboratorios de algunas de las crisis sobre la representación a través de la práctica artística y la reacción frente a esta. Así pues, actualmente, esta clase de sucesos están siendo revisitados para ampliar los límites en los que se les solía encasillar: que iban desde disputas religiosas hasta meros ataques emocionales y vandálicos. Por lo tanto, en el presente escrito se busca aproximarse a otra mirada sobre la iconoclasia que tiene presente las teorías sobre la plusvalía de las imágenes compartidos por autores como W.J.T Mitchell o David Freedberg. Con este propósito, se trata de encontrar otras definiciones al acto violento contra las imágenes, convirtiéndose este fenómeno en una posible teoría del disenso. Se defiende, de este modo, un campo de estudio que analiza los eventos destructivos como un escenario del agonismo que articula cambios en las comunidades sociales desde sus propias representaciones y el pensamiento tras estas.
\end{abstract}

Palabras clave: Iconoclasia, Disenso, Imagen, Historia cultural 


\section{Introducción}

¡La locura os consumirá! grita Yogg-Saron durante su enfrentamiento en el videojuego WORLD OF WARCRAFT. Durante el encuentro, la propia visión de este jefe de banda hace que los jugadores pierdan cordura hasta el punto de poder morir. El hecho de que la locura se pierda a raíz de la propia figura del monstruo se relaciona con otros mitos de la imagen y su recepción, como puede ser el de Medusa y la petrificación física a través de la mirada. Esta respuesta o reacción frente a las imágenes es la que cabe analizar con mayor detenimiento debido a las emociones que suscitan como pueden ser la locura o la agresividad y, por ende, las acciones que se toman frente a estas. Sin embargo, estos estados, considerados extremos contra las imágenes, son parte de la naturaleza de la producción artística y su registro cultural. Entre los casos vinculados con estas reacciones agresivas o negacionistas hacia las imágenes se encuentran los fenómenos iconoclastas, los cuales han sido relegados a eventos puntuales, históricos y de índole religiosa. A lo largo del tiempo, la destrucción de imágenes no ha sido debidamente analizada por la academia, ya que han sido vistos como trastornos psicológicos y vandálicos, más propios del análisis de las ciencias médicas que de las humanidades. Por ello, en este artículo, se busca adecuarse a las corrientes de estudio que, en las últimas décadas, han propuesto acercarse a la iconoclasia como un capítulo imprescindible para la comprensión de la historia cultural y la plusvalía de las imágenes, desde la experiencia estética hasta la politización en la producción de estas. Es, por tanto, fundamental tratar de trazar en este escrito un arco histórico en el que se recojan varios ejemplos de conflictos sobre las imágenes que muestren cómo el disenso es parte intrínseca de estos actos y, a su vez, reflexionar sobre estos casos de estudio en el que el disenso aún está en una fase de experimentación que no se ha sabido llevar a ningún puerto estable.

El objetivo principal de este artículo, por lo tanto, se basa en proporcionar conexiones entre los gestos iconoclastas y su respuesta. Para ello, se necesita ejemplificar este gesto destructivo iconoclasta como posible teoría del disenso, tomando este campo como un laboratorio en el que las imágenes son las protagonistas y ponen en práctica el análisis, ya no solo de las diferencias sino también de las posibilidades de yuxtaposición de intereses políticos y estéticos. A pesar de la brevedad en la que se ha de trazar esta cartografía, los ejemplos tratarán de aproximar una idea de diferentes ataques iconoclastas llevados a cabo por multiples motivos, teniendo únicamente en común el rechazo frente a una idea contraria. La metodología empleada en este artículo versa sobre el estudio de casos de análisis en los que se puedan ver reflejadas estas crisis entorno a las imágenes y en la puesta en común de las teorías que tratan de incorporar la iconoclasia como valor de estudio autónomo. La finalidad, así pues, es conseguir mediante una hermeneútica de los textos de los autores que estudian estos casos y una metodología de carácter cualitativo, el proponer otros factores de análisis a las respuestas sociales frente a las imágenes, siendo estas mismas posibles experimentos sobre el disenso llevados a cabo por el conflicto. 


\section{Una aproximación cartográfica de la iconoclasia histórica}

Los estudios académicos han ido incorporando la iconoclastia como un valor de análisis gracias al trabajo de autores como David Freedberg o Dario Gamboni, los cuales han tratado de recuperar y revalorizar un nuevo punto de vista hacia estos actos contra las imágenes. Dichos gestos han llegado a ser denominados como teorías de la respuesta, ya sea desde una perspectiva psicológica (Freedberg, 2017), por reacciones antropológicas (Belting, 2012) o, incluso, por su carácter ideológico (Mitchell, 2017). Por ello, en los estudios actuales que entroncan con la recuperación histórica y/o sobre los efectos de las imágenes, es necesario que se tomen en cuenta los casos iconoclastas. Sin embargo, no es una cuestión meramente cognitiva o perceptual (Arnheim, 1981), sino que, en la línea de nuevos enfoques metodológicos como pueden ser los procedentes de los estudios visuales, se trata de experimentar con otras perspectivas que se vinculen hacia los métodos de producción, en los cuales entran en juego factores políticos y sociales. Por ello, una interesante vía de análisis de los gestos iconoclastas son los que, más allá del acto punitivo, observan factores socio-políticos que provocan ese tipo de respuestas. Es, por ello que, para poder hacer una cartografía de la cuestión que ayude a conectar cómo la iconoclasia podría ser un laboratorio del disenso colectivo, es necesario hacer una breve cartografía que ayude a ilustrar algunos ejemplos que pongan de relieve un punto de partida con el cual reflexionar sobre el conflicto en las imágenes y extraer una posible vía de debate.

En el año 726 el emperador bizantino León III mandó sustituir una imagen de Cristo de la puerta de Calcis por una cruz. Esta primera crisis iconoclasta duró hasta el año 787 en el que, durante el II Concilio de Nicea, Juan Damasceno y sus tesis iconódulas argumentó cómo Dios había revocado su propia ley al hacer al hombre "a su imagen" y semejanza, llegando al punto de encarnarse en la figura de su Hijo. El ser humano sería, por tanto, reflejo de la imagen de Dios. De este modo, los debates al respecto de la idea de la Verdad sobre la representación de lo divino abrieron un campo sobre la práctica artística y lo que concierne a la representación de conceptos relacionados con lo Absoluto e, incluso, lo irrepresentable. A partir de este momento, aunque no siendo el primero en la Historia, se fueron sucediendo los argumentos hacia una mayor complejidad de reflexión de la posibilidad de las imágenes. Las teorías favorables a la representación se complementaron con aportaciones de autores como las de Santo Tomás de Aquino el cual, reinterpretando a Aristóteles, distinguió entre la imagen en sí y la imagen en tanto que otra imagen (Delgado, 1997, p. 5). De este modo, reafirma la distinción entre veneración e idolatría en favor de la primera. Esto es debido a que la exaltación emocional podría distorsionar la percepción de una imagen confundiendo a la divinidad con su figura objetual o, lo que es lo mismo, la distinción entre el concepto o idea de su representación material. Estos argumentos buscaban poder dar respuesta a las reacciones hacia las imágenes y generar de este modo un buen ver ético hacia las mismas, matizando los conflictos entorno a sus significados y su materialización física, una argumentación que a día de hoy puede verse en las propuestas antropológicas de Hans Belting en las que distingue la imagen como la idea inmaterial y su necesidad de verse materializada físicamente mediante un medio o soporte (2012). Estos planteamientos ponen de relieve el papel inmaterial de la imagen, resaltando la ineficacia de censurar o destruir los objetos representados, ya que a pesar de su destrucción las ideas tras esas imágenes continuarían perdurando (Huberman, 2009).

Sin embargo, los actos destructivos no cesaron a pesar de los argumentos iconódulos. Dos ejemplos históricos de este tipo de reacciones frente a las imágenes que desencadenaron fuertes periodos iconoclastas son la Beeldenstorm del siglo XVI y la Revolución Francesa. El primero, vinculado con la Reforma protestante en la zona de lo que hoy se conoce como los Países Bajos, tiene sus antecedentes en la figura del monje Wycliff el cual era disentía de las normas hacia las imágenes y promulgó que se podía prescindir de estas para el culto. Dichas ideas fueron recogidas más tarde por Von Karlstadt que, en 1522, las publicó generando una osmósis entre la iconoclasia violenta y una iconoclasia legal, dando pie a la purga dentro de los espacios religiosos (y ninguno en espacios civiles) contra la mayoría de las imágenes de culto, siendo estos ataques amparados por la ley. Por el otro lado, debido a la Revolución Francesa, los gestos destructivos no eran, en sí, contra la representación divina sino hacia la representación monárquica, es decir, política. Todo lo que pudiese recordar al Antiguo Régimen era destruido, como fue la retirada de la escultura de Napoléon de la plaza de Vendôme en 1871. Sin embargo, los actos iconoclastas pueden llegar a ser la suma de este tipo de desencadenantes convirtiéndose en casos más complejos de estudio. Esto sucede con los análisis de los ataques llevados a cabo, antes y durante, en la Guerra Civil Española. Estos han sido vinculados no exclusivamente a ataques contra el cristianismo o su representación, sino por la vinculación política de la iglesia en los eventos del país en dicho contexto histórico. (Delgado, 2012) 
Visto desde el prisma que se escoja, en todos los casos iconoclastas hay un disenso de origen que busca una alternativa contra lo que se rechaza. En prácticamente todos los casos que se suelen presentar predomina el gesto violento, por lo que no se está frente a un disenso que trate de encontrar un entendimiento común, sino una imposición hegemónica frente al alzamiento de otra posible supremacía. Esto implica, por ende, la conversión de los símbolos y la representación de una cultura frente a otra, una fagocitación de las ideas de uno contra lo Otro. Sin embargo, las estrategias del disenso sobre la imagen no siempre fueron meramente iconoclastas, también existieron soluciones iconódulas. Esto es el caso del sincretismo religioso que se generó al proclamar a Serapis divinidad patrona de la ciudad de Alejandría por Ptolomeo I Sóter en el siglo III a.c. Esta figura divina, que resulta de la hibridación de elementos mitológicos griegos y egipcios, buscaba aunar ambas culturas bajo nuevas imágenes que las entrelazaran. Esto no implica que no se formaran respuestas negativas contra Serapis, debido también a la palpable hegemonia y privilegio griego. A pesar de ello, este dios se convirtió en un símbolo del intento de trabajar ante el disenso cultural en una resolución, a priori pacífica, para ambas culturas.

\section{La plusvalía de las imágenes}

Sin embargo, las propias raíces etimológicas de la palabra iconoclasia, eikonoklastés, tienen su complejidad. Imagen (Eikon) y la acción de romper (Klao) conforman el acto de la iconoclasia vinculado a los que destruían imágenes de culto, siendo imagen el concepto más confuso en su análisis filológico. Esta palabra en latín se relaciona con la copia, la imitación y con la figura del fantasma, incluso el historiador Alain Besançon matiza que en hebreo puede llegar a significar vanidad, mentira o para referirse a la nada (2003). Desde el propio lenguaje se ha construido una herencia sobre la imagen que lo vincula con el mundo del engaño o la imitación, con la mera ilustración. Así pues, esta herencia se ha mantenido en las teorías sobre la imagen del siglo XX. Prueba de ello son los argumentos de Walter Benjamin sobre los nuevos medios de producción visual (2011) o, más actualmente, las teorías sobre los medios de comunicación y el uso de las imágenes que se centran en estrategias capitalistas y especulares, llegando estas a convertirse en puros simulacros, como llegaría a denominarlos Baudrillard (2016) o en espectacularmente especulares como apunta Debord (1999).

Debido a esto, algunas de las teorías entorno a la imagen han trabajado sobre las líneas de la imitación o el engaño, llegando hasta nuestros días. Por otro lado, en paralelo a estos enfoques sobre lo visual, un nuevo valor de estudio ha comenzado a emplearse a la hora de estudiar las imágenes: su plusvalía. Este factor trata de analizar ya no solo posibles significados intrínsecos en la imagen, sino su valor contextual de recepción, no siendo esto como una mera iconología. Un caso conocido de plusvalía es la destrucción de los Budas de Bamiyán, acción llevada a cabo por considerarse iconos por los talibanes afganos. Sin embargo, no todos están tan seguros de sus motivos religiosos y ven en esta aniquilación de patrimonio un ataque frente a la cultura turística y del consumo promovida por los países occidentales (Vives-Ferrándiz, 2015). De este mismo modo, varios de los ataques producidos por el Daesh se han catalogado como ataques iconoclastas, un hecho que ayuda a ver las acciones de este grupo terrorista como actos vandálicos propio de bárbaros y no de una planificación más elaborada (Gamboni, 2014). Los ataques al patrimonio y sobre la sociedad musulmana ejercidos por el Daesh podrían ser también ataques contra el capitalismo y la cultura occidental, gestos que puedan provocar terror geopolítico debido a su plusvalía contextual. En esta línea, otro claro ejemplo del empleo de este valor visual es la guerra periodística que se generó a raíz del ataque terrorista del 11-S. Estados Unidos empleó su propia historia visual para justificar la guerra contra Oriente, mientras que Europa propuso un replanteamiento del conflicto bélico empleando las imágenes de su propia historia reciente, como las sufridas en la II Guerra Mundial (Huberman, 2018).

Por todo ello, esta plusvalía que parecen tener las imágenes es una de las herramientas que se emplean para analizar estos casos iconoclastas contemporáneos y dar respuesta a otros posibles motivos intrísecos de dichos actos que no son meramente el conflicto representativo o filosófico. Así pues, a las teorías sobre lo visual y las imágenes, se están añadiendo nuevos métodos de estudio que amplían la posibilidad de aproximarse a la naturaleza de lo que se considera como una imagen, siendo este debate uno de los más trabajados en las últimas décadas (García, 2011). Pero como se ha podido ir observando a lo largo del texto, estos casos no deberían quedar relegados al margen de los estudios académicos sino que podrían ser fuente de aprendizaje hacia otras posibilidades de recepción. Se valoraría, entonces, reflexionar a raíz del estudio de los casos iconoclastas para profundizar en conceptos como el conflicto y la dicotomía de disenso/consenso. Dicha relación se ha acercado más a las resoluciones consensuales que se han asociado con los modelos representacionales 
democráticos de las sociedades actuales en la práctica política. Sin embargo, el uso del consenso no permite una vision detallada de las posibilidades de diferencia que se generan a través del disenso, marginando las minorías frente a las mayorías. A pesar de ello, las estrategias que han tratado de dar respuesta al uso del conflicto como herramienta de pensamiento, como pueden ser las propuestas arqueológicas de Foucault (2017), tampoco han dado una alternativa real al consenso. Es por ello, que aún resulta necesario reflexionar sobre el uso del disenso. Del mismo modo que la definición de conceptos como imagen o iconoclasia se están ampliando y enriqueciendo, lo mismo debería ir sucediendo en el uso del disenso como herramienta efectiva para evolucionar política y socialmente.

\section{Conclusiones}

Retomando, por tanto, la hipótesis planteada, puede confirmarse la utilidad del estudio de los casos iconoclastas como gestos del disenso y, de ese modo, analizar cómo han afectado a sus respectivos contextos socio-políticos. Los planteamientos de estudio al respecto de estos gestos entroncan con múltiples teorías sobre la imagen que buscan dar una respuesta a estas reacciones, siendo positivo que estos enfoques se incluyan en los debates académicos cómo algo más allá de un trastorno psicológico. La iconoclasia, por tanto, no es exclusivamente de índole religiosa o crisis de representación, sino que también puede proceder de disputas políticas y culturales, llegando incluso a introducirse en los discursos estéticos. Actualmente, las teorías sobre la iconoclasia también se están relacionado sobre modos de comprender la contemporaneidad incorporando conceptos como la idolatría en las teorías de los medios de comunicación en masas y la cultura del consumo, tal y como plantean Boris Groys o Hans Belting sobre la idolatría ante lo visual y los mass media (AAVV, 2012). Es por ello que se debe tener presente que la recepción de las imágenes que generan las sociedades crean disputas y conflictos, crean disenso. Este es el punto en el que se puede comenzar a trabajar la iconoclasia como una posible teoría sobre el disenso y emplearla como un laboratorio del conflicto en el que replantear las cuestiones que rodean las diferencias culturales y políticas. Del mismo modo que tradicionalmente se ha trabajado con la imagen sobre teorías que las vinculan con el engaño o la imitación, también se está levantando un movimiento que trata de argumentar en favor de estas, lo que se puede observar en autores como Marina Garcés, Jacquès Rancière, George Didi-Huberman o David Freedberg. Así pues, se debe trabajar con las heterogeneidades de las imágenes y tomar todas sus perspectivas para poder trabajar con un exhaustivo análisis de las mismas. A pesar de la concisión llevada a cabo en este artículo, se puede abrir un debate entorno a las múltiples maneras de entender la iconoclasia y cómo esta puede ser empleada para trabajar sobre el disenso. Trabajar sobre esta base puede permitir que se amplie el conocimiento que se tiene sobre el conflicto y permitir nuevas oportunidades de reacción frente a este. En conclusión, este enfoque ayudaría a que la reacción frente a la diferencia no sea la violencia a la imagen, sino la incorporación de esta a una cartografía social mutable y en movimiento, un movimiento que ha de ser común, ya que la locura nos consumirá si dejamos que esta sea la que guíe nuestro entendimiento frente al desacuerdo. 


\section{Referencias bibliográficas}

Álvarez Otero, C. (Ed.) (2012). Iconoclastia. La ambivalencia de la mirada. Madrid: La Oficina de Arte y Ediciones, S.L.

Arnheim, R. (1981). Arte y percepción visual. Psicología del ojo creador. Madrid: Alianza.

BAUdRILlard, J. (2016). Cultura y simulacro (n ${ }^{\mathrm{a}} 12$ ed.). Barcelona: Editorial Kairós S.A.

Belting, H. (2012). Antropología de la imagen (3 ${ }^{\mathrm{a} e d .) . ~ E s p a n ̃ a: ~ K a t z ~ E d i t o r e s . ~}$

Benjamin, W. (2011). La obra de arte en la época de la reproductibilidad mecánica. Madrid: Casimiro.

BESANÇON, A. (2003). La imagen prohibida: una historia intelectual de la iconoclasia. Madrid: Siruela, D.L.

Debord, G. (1999). La sociedad del espectáculo. Valencia: Pre-Textos, cop.

Delgado, M. (1997). “Exorcismo y martirio de las imágenes. La iconoclastia como violencia corporal” en Checa, F; Molina, P. (Ed.). La función simbólica de los ritos: rituales y simbolismo en el Mediterráneo. España: Icaria, Instituto de Estudios Almerienses.

Delgado, M. (2012). La ira sagrada. Anticlericalismo, iconoclastia y antirritualismo en la España contemporánea. Barcelona: RBA Libros, S.A.

Didi-Huberman, G. (2009). La imagen superviviente: historia del arte y tiempo de los fantasmas según Aby Warburg. Madrid: Abada, D.L.

Didi-Huberman, G. (2018). Cuando las imágenes tocan lo real. Madrid: Círculo de Bellas Artes.

Foucault, M. (2017). La arqueología del saber (n 4 ed.). México: Siglo XXI Editores, s.a. de c.v.

FREEDBERG, D. (2009). El poder de las imágenes: estudios sobre la historia y la teoría de la respuesta. Madrid: Ediciones Cátedra.

FreEdBerg, D. (2017). Iconoclasia. Historia y psicología de la violencia contra las imágenes. Vitoria-Gasteiz: Sans Soleil Ediciones.

GAmboni, D. (2014). La destrucción del arte. Iconoclasia y vandalism desde la Revolución Francesa. Madrid: Ediciones Cátedra.

GArcía, A. (Ed.) (2011). Filosofia de la imagen. Salamanca: Ediciones Universidad de Salamanca.

MitcheLl, W.J.T. (2017). ¿Qué quieren las imágenes? Una crítica a la cultura visual. Vitoria-Gasteiz: Sans Soleil Ediciones.

Vives-Ferrándiz, L. (2015). “(No) son sólo imágenes: Iconoclasia y yihad 2.0.” en Anuario del Departamento de Historia y Teoría del Arte, Vol. 27. Madrid: Departamento de Historia y Teoría del Arte (UAM) < https://revistas.uam.es/anuario/article/view/7324> [Consulta: 14 de septiembre de 2019]. 